\title{
Factors affecting the success of pediatric extracorporeal shock wave lithotripsy therapy: 26-year experience at a single institution
}

\author{
Fuat Kızılay $^{10}$, Turan Özdemir ${ }^{1}$, Burak Turna ${ }^{1}$, Nursen Karaca ${ }^{2}$, Adnan Şimşirir ${ }^{1}$ \\ Işık Alper'², Oktay Nazl1 ${ }^{1}$ \\ Departments of ${ }^{1}$ Urology and ${ }^{2}$ Anaesthesiology, Ege University Faculty of Medicine, Izmir, Turkey.
}

\begin{abstract}
Despite its widespread use, few studies have evaluated the success of extracorporeal shock wave lithotripsy (ESWL) in pediatric patients with several parameters and a large group of patients. In the present study, we aimed to analyze the factors that affect the outcomes of pediatric ESWL treatment, which we have practiced for 26 years. This study included 1012 pediatric patients who underwent ESWL between March 1991 and November 2017. Pre-procedure radiological evaluations were performed using kidney-ureter-bladder and/ or urinary system ultrasonography. Demographic data, stone characteristics, and ESWL treatment data and complications were recorded and univariate and multivariate analyses were performed for the stone-free rate (SFR). Receiver operating characteristic (ROC) analysis was performed to determine the cut-off values for stone size to predict ESWL success for both kidney and ureteral stones. Age, body mass index (BMI), congenital renal anomaly, stone location, stone size, number of stones, and stone composition significantly affected the SFRs in univariate analysis; however, only age, BMI, stone location, and stone size were significant in the multivariate analysis. If no residual fragments were detected after three sessions of ESWL application, the procedure was considered successful. The cut-off stone size values for the kidney and ureter that predicted treatment success were $96.28 \mathrm{~mm}^{2}$ and $44.16 \mathrm{~mm}^{2}$, respectively. ESWL is an effective and safe treatment in the pediatric age group that provides high SFRs. Age, BMI, and stone location, size, and composition are particularly critical factors that can predict the success of ESWL.
\end{abstract}

Key words: urolithiasis, pediatric urology, extracorporeal shock wave lithotripsy, stone disease, ureteral stone.

The aim of urinary stone treatment is to provide stone elimination with the least morbidity and greatest success rate. ${ }^{1}$ Technological advances have replaced invasive procedures, such as open surgery, with more non-invasive methods, such as extracorporeal shock wave lithotripsy (ESWL), ureteroscopy, and percutaneous nephrolithotomy. ESWL has been used worldwide since Chaussy et al. ${ }^{2}$ first used ESWL to treat kidney stones in 1980.

$凶$ Fuat Kizilay

fuatkizilay@gmail.com

Received 6th August 2018; revised 19th November 2018; accepted 24th December 2018
The first ESWL applications in pediatric patients was carried out in 1986 by Newman et al. ${ }^{3}$ After this series, several short-term studies were published regarding the use of ESWL in pediatric patients. ${ }^{4,5}$ In children, ESWL has significant advantages that make it the first treatment option in eligible patients: its non-invasive nature, outpatient applicability, lower complication rates compared to surgical approaches, replicability (because stone recurrence is more common in children than in adults), and the ease of passage of ESWLbroken fragments in children. ${ }^{6,7}$

Despite its widespread use, few studies have evaluated the use of ESWL in pediatric patients with several parameters in large patient groups. The number of samples was small in 
some studies ${ }^{8}$ and, in some of them, factors that could affect the results, such as stone side and size, were missing. ${ }^{9}$ In the present study, we analyzed the data, over a 26-year period, of 1012 pediatric patients who underwent ESWL treatment and aimed to evaluate the factors that affected ESWL outcomes in our cohort.

\section{Material and Methods}

\section{Patient selection and preparation}

Between March 1991 and November 2017, the data of 1012 pediatric patients who underwent ESWL treatment were retrospectively analyzed. Patients with a kidney stone smaller than 2000 $\mathrm{mm}^{2}$ and ureteral stone smaller than $144 \mathrm{~mm}^{2}$, with complete imaging and laboratory data and patient records, without previously failed ESWL history (a total of 3 sessions), accepting the risks of ESWL and general anesthesia, and who were fit for anesthesia, were included in the study. ESWL was not performed in patients with active urinary infection, uncontrolled bleeding diathesis, or distal obstruction or who were unsuitable for general anesthesia. All patients were assessed via urinalysis, complete blood count, blood chemistry, and bleeding and clotting time prior to ESWL. Pre-procedure radiological evaluations were performed using X-ray plain abdominal film of kidneyureter-bladder (KUB) and/or urinary system (US) ultrasonography. US ultrasonography, KUB and both of them were performed in 685, 150 and 177 patients, respectively. Informed consent was obtained from all parents before the procedure. The study was conducted in accordance with the Helsinki declaration, and the Institutional Review Board of Ege University approved the study (decision number: 19-3/2, date: 18.12.2017).

\section{Anesthesia method}

Anesthesia was induced via a facemask with $8 \%$ sevoflurane in $100 \%$ oxygen $\left(\mathrm{O}_{2}\right)$ and the rate of sevoflurane was gradually reduced without spontaneous respiratory depression and closed after an intravenous cannula was indwelled. Afterward, an intravenous infusion of $0.9 \%$ sodium chloride $(\mathrm{NaCl})$ was started and $10 \mu \mathrm{g} / \mathrm{kg}$ atropine, $0.05 \mathrm{mg} / \mathrm{kg}$ midazolam, and $0.5-1 \mathrm{mg} / \mathrm{kg}$ ketamine as a slow bolus over $60 \mathrm{~s}$ were administered and 5-6 L/min $\mathrm{O}_{2}$ support was given via face mask during the procedure. Anesthesia was maintained with an additional dose of $0.5 \mathrm{mg} / \mathrm{kg}$ ketamine given according to clinical parameters, such as moving or moaning from pain induced by shock waves. Patients were discharged once they were fully recovered from anesthesia and their vitals were stabilized, nausea, vomiting, and pain were controlled, and when they reached their first time consciousness score.

\section{ESWL procedure}

ESWL was performed using a Dornier MPL 9000 from March 1991 to November 2010 in 607 patients and an ELMED Multimed Classic from November 2010 to November 2017 in 405 patients. Two urologists who were experienced in pediatric stone disease treatment supervised allESWL procedures(O.N. and B.T.). In theESWL procedure, shock waves were boosted up to a maximum of 20-22 kV energy starting from low values. The total number of shock waves applied per session generally exceeded 2000 pulses. The number of sessions was in the range of 1 to 4 and applied at 15-20 day intervals. During the ESWL procedure, we stopped the therapy when the maximal number of predetermined shocks was reached in the absence of a visualized stone. If any stones remained un-fragmented at the end of 3 sessions, the ESWL was considered a failure and other treatment options took place. However, after 3 sessions, after a while, additional ESWL sessions were applied to some children whose parents did not accept surgical treatment options and/or whose stones were partially fragmented. Stone analysis could be obtained in a small proportion of patients and further treatment was initiated. Patients were checked with KUB and/or US ultrasonography at intervals of 20 days and the ESWL procedure was repeated when indicated. Indications for repeat-ESWL were residual fragment detection 
in control imaging. If the child was found to be out of stone, the next control was carried out at 6 months and one every 6 months thereafter. After a total of 3 ESWL sessions, children without residual fragments were considered stone-free; otherwise, the procedure was considered unsuccessful. Stone free was accepted as the absence of any fragments in control imaging methods. Fragments less than $4 \mathrm{~mm}$ were considered clinically insignificant residual fragments. However, the criteria for success and statistical analysis was stone free status. The patients were also divided into two groups (Group A and B) according to lithotriptor devices used and stone-free rates were compared between the two groups.

\section{Data collection}

The stone size was calculated in square millimeters by multiplying the longest diameter of the stone by the longest perpendicular diameter detected in the imaging method. In the case of multiple stones, total stone burden was calculated by adding up the volume of each stone. The following values were retrospectively analyzed: age, gender, body mass index (BMI), family history, previous surgery history, congenital kidney anomaly status of the patients, the location and size of the stone in the kidney or ureter, stone composition, double J stent (DJS) requirement, hydronephrosis status, shock wave number and energy applied per session, total number of sessions, outcome (stone-free, fragmented, or ineffective), control method for stone-free, anesthesia method, complications, and residual stone number and size. The family history of patients with stone history in the first degree relatives, was accepted as positive. The primary outcome measurement of the study was the stone-free rate; identifying which variables affected the stone-free status was the secondary outcome measurement. Since the control of stone-free status with only KUB might affect the stone-free rate, 150 patients undergoing only KUB after ESWL were then excluded from the study and a subgroup analysis of the remaining 862 patients was performed.

\section{Statistical analysis}

Categorical measurements were recorded as number and percentage, whereas continuous measurements were recorded as the mean and standard deviation (median and minimummaximum when necessary). The ShapiroWilk test was used to test the normality of the variables. Student's t-test was used to compare continuous measures between stone-free and non-stone-free groups and the Chi-squared test was used to compare categorical variables. Logistic regression analysis was performed to identify the independent risk factors that affected the success rate. Multivariate analysis was performed for variables that were significant in univariate analysis to determine the predictive factors. A cut-off value was also determined for the statistically significant values among the groups and the area under the receiver operating characteristic (ROC) curve was evaluated by calculating the sensitivity and specificity values. SPSS 23.0 was used for statistical analysis. Statistical significance was accepted as $\mathrm{p}<0.05$.

\section{Results}

A total of 1012 patients were treated with ESWL. The mean age of children was $6.6 \pm 1.18$ years ( 8 months -18 years). The vast majority of patients were boys (644/368). ESWL treatment was most commonly applied for kidney stones $(915 / 1012)$ with a mean stone size of $118.5 \mathrm{~mm}^{2}$ and a mean number of shock wave count of 2949. Complications (steinstrasse, the German word for "stone street", describing a possible complication of ESWL for urinary tract calculi wherein a column of stone fragments forms that blocks the ureter) were seen in only 20 patients (1.97\%). Conservative medical treatment was initiated for the patients with steinstrasse. However, 8 patients did not benefit and underwent ureteroscopy. Ureteral catheters were placed at the time of surgery to help to locate the stone in 96 patients (9.5\%).

Stone-free-rate (SFR) was higher in younger children with lower BMI (p: 0.024, p: 0.018, 
respectively) but significantly lower in children with congenital kidney anomalies (p: 0.032). Thirteen children had horseshoe kidneys, 13 children had duplex collecting systems, and 7 children had pelvic kidneys obstruction anomalies. After ESWL treatment, the total number of stone-free children for both kidneys and ureter stones was higher than children with residual stones (p: 0.015, p: 0.029, respectively). The stone's location in the urinary system affected the SFR: in the kidney, SFR was higher for stones in the renal pelvis, upper calyx, and middle calyx (p: 0.011, p: 0.048 and $\mathrm{p}: 0.014$, respectively), while it was higher for the proximally located stones in the ureter $(\mathrm{p}$ : 0.035). In both the kidney and ureter, the mean stone volume was lower in the stone-free group (p: 0.019 and p: 0.022, respectively). When the number of stones was evaluated for ESWL success, there were significantly fewer stones in the kidney in the stone-free group than in the non-stone-free group (p: 0.017); nevertheless, there was no significant difference between the groups regarding ureteral stones (p: 0.355). Stone analysis was obtained from passing stones in sixty-six patients and the SFR was lower in calcium phosphate, calcium oxalate, and cystine stones (p: 0.012, p: 0.038 and p: 0.044, respectively). Children who underwent stone analysis were referred to the pediatric nephrology with the aim of prophylactic treatment. Patient and stone data and univariate analysis of the predictive variables for ESWL success and information on ESWL procedure and complications are given in Tables I and II.

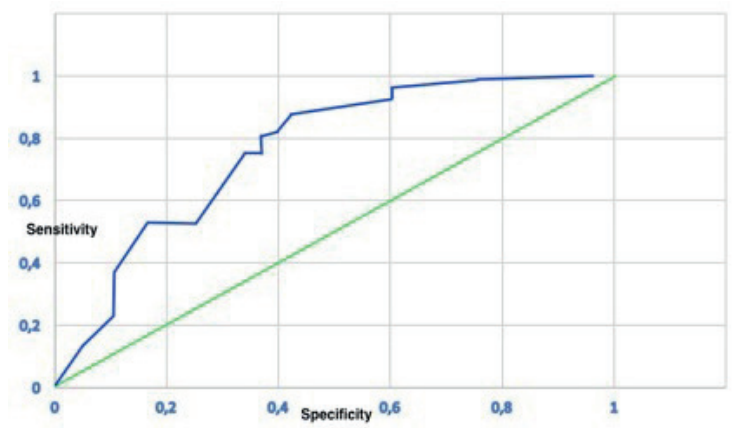

Fig. 1. ROC curve of cut-off value for kidney stone size.
Multivariate analysis of the variables for stonefree status are summarized in Table III and age, BMI, renal pelvis location, upper calyx location, proximal ureter location, and stone size were independent predictors of SFR. The cut-off kidney and ureteral stone size values for treatment success were $96.28 \mathrm{~mm}^{2}$ and 44.16 $\mathrm{mm}^{2}$, respectively, as shown in Table IV (for ROC curves, see Figs 1 and 2).

In the subgroup analysis of 862 patients [patients evaluated with only kidney-ureterbladder (n: 150) were excluded) who underwent ultrasonography post-ESWL, we found that age, stone location and size were important factors affecting SFR and those data were summarized in Table V. We have not added ureteral stones to this analysis because the diagnostic efficiency of ultrasonography in ureteral stones is low.

Patients were divided into two groups in order to determine whether there was device dependent variability in SFRs, and SFR was higher in patients treated with the new generation device (92\% vs. $73 \%$, p: 0.042). The comparison of the two groups according to the lithotriptor device used is summarized in Table VI.

\section{Discussion}

Pediatric urolithiasis is a significant disease with frequent recurrences and significant morbidity in children. Nowadays, modern treatment methods of this disease are minimally invasive interventions in both children and adults. ESWL therapy has not been approved by the Food

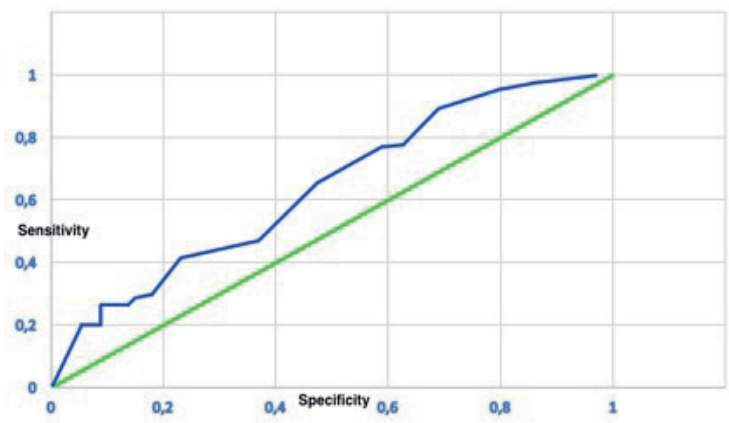

Fig. 2. ROC curve of cut-off value for ureteral stone size. 
Table I. Patient and stone characteristics and univariate analysis of the variables.

\begin{tabular}{|c|c|c|c|c|}
\hline Characteristics & Total & Stone-free & Non-stone-free & $\mathrm{p}$ value \\
\hline Number of patients, $\mathrm{n}(\%)$ & $1,012(100)$ & $815(80.5)$ & 197 (19.5) & 0.038 \\
\hline Age, years* & $6.6(0.58-18)$ & $5.6(0.58-12)$ & $8.2(1.2-18)$ & 0.024 \\
\hline Gender, n (\%) & & & & 0.166 \\
\hline Boys & $644(63.6)$ & $302(46.8)$ & $342(53.2)$ & \\
\hline Girls & $368(36.4)$ & $172(46.7)$ & $196(53.3)$ & \\
\hline Body mass index, $\mathrm{kg} / \mathrm{m}^{2 *}$ & $23.2(17.3-28.6)$ & $19.4(17.8-22.5)$ & $24.2(23.6-28.6)$ & 0.018 \\
\hline Family history, n (\%) & & & & 0.362 \\
\hline Yes & $237(23.4)$ & $125(52.7)$ & $112(47.3)$ & \\
\hline No & $775(76.6)$ & $393(50.7)$ & $383(49.3)$ & \\
\hline \multicolumn{5}{|l|}{ Previous surgery, n (\%) } \\
\hline Yes & 155 (15.3) & $81(52.2)$ & $74(47.8)$ & \\
\hline No & $857(84.7)$ & $442(51.5)$ & $415(48.5)$ & \\
\hline \multicolumn{5}{|c|}{ Congenital kidney anomaly, n (\%) } \\
\hline Yes & $33(3.2)$ & $12(36.3)$ & $21(63.7)$ & 0.032 \\
\hline No & $979(96.8)$ & $512(52.3)$ & $467(47.7)$ & \\
\hline \multicolumn{5}{|l|}{ Stone location, n (\%) } \\
\hline Kidney & $915(90.4)$ & 777 (84.9) & $138(15.1)$ & 0.015 \\
\hline Renal pelvis & $584(63.8)$ & $523(89.2)$ & $61(10.8)$ & 0.011 \\
\hline Upper calyx & $172(18.8)$ & $149(86.6)$ & $23(13.4)$ & 0.048 \\
\hline Middle calyx & $122(13.4)$ & $89(72.3)$ & $33(27.7)$ & 0.014 \\
\hline Lower calyx & $37(4.0)$ & $19(52.2)$ & $18(47.8)$ & 0.560 \\
\hline Ureter & $97(9.6)$ & $84(87.2)$ & $13(12.8)$ & 0.029 \\
\hline Proximal ureter & $76(78.3)$ & $62(81.5)$ & $14(18.5)$ & 0.035 \\
\hline Distal ureter & $21(21.7)$ & $12(57.2)$ & $9(42.8)$ & 0.228 \\
\hline Stone side, $\mathrm{n}(\%)$ & & & & 0.644 \\
\hline Kidney & 915 (90.4) & $450(49.2)$ & $465(50.8)$ & \\
\hline Right & 487 (53.2) & $252(51.7)$ & $235(48.3)$ & \\
\hline Left & $428(46.8)$ & $198(46.2)$ & $230(53.8)$ & \\
\hline Ureter & $97(9.6)$ & $43(44.3)$ & $54(55.7)$ & \\
\hline Right & $52(53.6)$ & $22(42.3)$ & $30(57.7)$ & \\
\hline Left & 45 (46.4) & $21(46.6)$ & $24(53.7)$ & \\
\hline Stone size, $\mathrm{mm}^{2 *}$ & $118.5(12-1,680)$ & & & \\
\hline Kidney & & 78.5 (12-98) & $118.4(28-1,680)$ & 0.019 \\
\hline Renal pelvis & $127(25-1,680)$ & & & \\
\hline Upper calyx & $90.7(25-300)$ & & & \\
\hline Middle calyx & $74.7(12-274)$ & & & \\
\hline Lower calyx & $75.4(25-625)$ & & & \\
\hline Ureter & & $38.6(20-68)$ & $72.4(34-121)$ & 0.022 \\
\hline Proximal ureter & $61.4(20-121)$ & & & \\
\hline Distal ureter & $31.4(25-50)$ & & & \\
\hline
\end{tabular}

*: data is presented as mean (minimum-maximum)

$p$ values $<0.05$ are given in italics 
Table II. Stone number, structure and information on extracorporeal shock wave lithotripsy (ESWL) procedure and complications.

\begin{tabular}{|c|c|c|c|c|}
\hline Features & Total & Stone-free & Non-stone-free & $p$ value \\
\hline Number of stones* & $1.29(1-5)$ & & & \\
\hline Kidney & & $1.02(1-2)$ & $1.89(1-5)$ & 0.017 \\
\hline Renal pelvis & $1.04(1-3)$ & & & \\
\hline Upper calyx & $1.16(1-5)$ & & & \\
\hline Middle calyx & $1.13(1-5)$ & & & \\
\hline Lower calyx & $1.34(1-3)$ & & & \\
\hline Ureter & & $1.08(1-2)$ & $1.26(1-2)$ & 0.355 \\
\hline Proximal ureter & $1.08(1-2)$ & & & \\
\hline Distal ureter & $1(1-1)$ & & & \\
\hline \multicolumn{5}{|l|}{ DJS before intervention, $\mathrm{n}(\%)$} \\
\hline Yes & $96(9.5)$ & $45(47.8)$ & $51(52.2)$ & \\
\hline No & $916(90.5)$ & $462(50.4)$ & $454(49.6)$ & 0.286 \\
\hline Number of shock waves * & $2,949(200-18,131)$ & $3,126(448-18,131)$ & $2,825(200-16,625)$ & 0.290 \\
\hline Stone composition, $\mathrm{n}(\%)$ & $66(6.52)$ & & & \\
\hline Ca-phosphate & $26(39.4)$ & $10(38.4)$ & $16(61.6)$ & 0.012 \\
\hline Ca-phosphate/Ca-oxalate & $16(24.2)$ & $7(43.7)$ & $9(56.3)$ & 0.744 \\
\hline Ca-oxalate & $11(16.6)$ & $3(27.2)$ & $8(72.8)$ & \\
\hline Cystine & $5(7.5)$ & $1(25.0)$ & $4(75.0)$ & \\
\hline Mg ammonium phosphate & $4(6.0)$ & $2(50.0)$ & $2(50.0)$ & 0.038 \\
\hline Ca-carbonate & $3(4.5)$ & $2(66.6)$ & $1(33.4)$ & 0.044 \\
\hline Xanthine & $1(1.5)$ & $1(100)$ & - & \\
\hline Additional intervention, $\mathrm{n}(\%)$ & & & $62(6.12)$ & \\
\hline Percutaneous nephrolithotomy & & & $17(27.4)$ & \\
\hline Cystolithotripsy & & & $2(3.2)$ & \\
\hline Ureterorenoscopy & & & $43(69.3)$ & \\
\hline Complication, $\mathrm{n}(\%)$ & & & $20(1.97)$ & \\
\hline Steinstrasse & & & $20(1.97)$ & \\
\hline
\end{tabular}

Ca: calcium, DJS: double J stent, Mg: magnesium

*: data is presented as mean (minimum-maximum)

$p$ values $<0.05$ are given in italics

and Drug Administration in the United States because of insufficient data on the long-term side effects in the pediatric population; however, it has been widely accepted worldwide since its first reported application ${ }^{3}$ and is currently being applied as a first-line treatment in urolithiasis treatment. In the present study, we aimed to analyze the factors that predict the efficacy of this method in a large group of patients.

In the literature, it is stated that the child's age is not a limiting factor for ESWL and that even infants can be treated easily. ${ }^{10}$ In the present study, both univariate and multivariate analyses showed that the mean age of the children in the stone-free group was lower. Better success in these children may be due to decreased stone burden, softer stone composition, better ureteral compliance, and less distance between the shock wave generator and the stone. ${ }^{11}$ In Alsagheer et al.'s ${ }^{12}$ study, ESWL was more successful in younger children and age was the only independent predictor of success in the multivariate analysis. More recently, Dogan et al. ${ }^{11}$ have developed a new nomogram for 
Table III. Multivariate analysis of statistically significant variables for stone-free status for extracorporeal shock wave lithotripsy.

\begin{tabular}{lcc}
\hline Variable & HR $(95 \% \mathrm{CI})$ & $\mathrm{p}$ value \\
\hline Age (years) & $1.13(0.56-2.65)$ & 0.028 \\
Body mass index $\left(\mathrm{kg} / \mathrm{m}^{2}\right)$ & $0.96(0.68-1.88)$ & 0.015 \\
Congenital kidney anomaly & $2.35(0.84-11.21)$ & 0.752 \\
Stone location & & \\
$\quad$ Kidney & $1.04(0.91-1.21)$ & 0.027 \\
$\quad$ Renal pelvis & $0.88(0.72-1.05)$ & 0.019 \\
$\quad 1.35(0.42-9.43)$ & 0.168 \\
$\quad$ Upper calyx & & \\
$\quad$ Middle calyx & $1.21(0.83-1.38)$ & 0.021 \\
$\quad$ Ureter & & \\
$\quad$ Proximal ureter & $1.19(0.90-1.31)$ & 0.048 \\
Stone size (mm $\left.{ }^{2}\right)$ & $0.98(0.82-1.18)$ & 0.011 \\
$\quad$ Kidney & & 0.788 \\
$\quad$ Ureter & $1.52(0.52-11.49)$ & 0.684 \\
Number of stones & $1.36(0.32-9.96)$ & \\
$\quad$ Kidney & DJS before intervention &
\end{tabular}

CI: confidence interval, DJS: double J stent, HR: hazard ratio,

$p$ values $<0.05$ are given in italics.

Table IV. Cut-off values calculated for kidney and ureteral stone size predicting shock wave success.

\begin{tabular}{lccccc}
\hline Parameter & Cut-off & AUC & Sensitivity & Specificity & p value \\
\hline Kidney stone size & $96.28 \mathrm{~mm}^{2}$ & 0.726 & $72.6 \%$ & $68.8 \%$ & 0.005 \\
Ureteral stone size & $44.16 \mathrm{~mm}^{2}$ & 0.768 & $70.8 \%$ & $67.2 \%$ & $<0.001$ \\
\hline
\end{tabular}

AUC: area under the curve

prediction of outcome of pediatric ESWL and stated that age is a risk factor for stone-free status in multiple logistic regression analysis and they included the age factor in their nomogram.

ESWL success is low in adult obese patients but obesity has not been shown to significantly affect the success of fragmentation in ESWL in the pediatric patient group. ${ }^{13,14}$ In our study, we found that, unlike current data, obesity is an important factor in ESWL success in multivariate analysis, likely because the age range in our patient group is very wide, the children are from different regions, and obesity in our society is seen in almost one in every three children.

Some studies show that congenital anomalies and even anomaly types in adult patients are important factors that affect ESWL success. ${ }^{15,16}$ In fact, in some studies, the presence of renal abnormalities was an exclusion criterion for the study. ${ }^{12}$ We found that renal anomalies were effective factors in univariate, but not multivariate analysis, likely because only a few patients had congenital anomalies and the majority of these anomalies were anomaly types that do not interfere with the passage of fragments.

Stone location is assumed to be an important factor affecting ESWL success; however, contradictory results exist in the literature about the effect of stone location on ESWL success, especially in ureter stones. The conclusions of the Bader et al. ${ }^{17}$ review were consistent with our results in that the SFR of proximal ureteral 
Table V. Patient and stone characteristics and univariate analysis of the variables in patients whose control was performed with urinary system ultrasonography [150 patients with only X-ray plain abdominal film were excluded].

\begin{tabular}{lcccc}
\hline Variable & Total & Stone-free & Non-stone-free & $\mathrm{p}$ value \\
\hline Number of patients, $\mathrm{n}(\%)$ & $862(100)$ & $678(78.6)$ & $184(21.4)$ & 0.022 \\
Age, years* & $6.8(0.61-17.5)$ & $5.2(0.61-14.4)$ & $8.4(1.0-17.5)$ & 0.013 \\
Stone location, $\mathrm{n}(\%)$ & & & & \\
$\quad$ Kidney & $765(88.7)$ & $662(86.6)$ & $103(13.4)$ & 0.029 \\
$\quad$ Renal pelvis & $509(66.5)$ & $443(86.8)$ & $66(13.2)$ & 0.007 \\
$\quad$ Upper calyx & $155(20.3)$ & $137(88.2)$ & $18(11.8)$ & 0.033 \\
$\quad$ Middle calyx & $92(12.0)$ & $68(73.4)$ & $24(26.6)$ & 0.041 \\
$\quad$ Lower calyx & $9(1.2)$ & $5(53.8)$ & $4(46.2)$ & 0.618 \\
Stone side, $\mathrm{n}(\%)$ & & & & 0.824 \\
$\quad$ Kidney & $765(88.7)$ & $377(49.2)$ & $388(50.8)$ & \\
$\quad$ Right & $414(54.1)$ & $209(50.4)$ & $205(49.6)$ & \\
$\quad$ Left & $351(45.9)$ & $168(47.8)$ & $183(52.2)$ & \\
Stone size, mm ${ }^{2 *}$ & $182.6(38-1,590)$ & $74.9(10-104)$ & $124.2(39-1,590)$ & 0.038 \\
$\quad$ Renal pelvis & $141(49-1590)$ & & & \\
$\quad$ Upper calyx & $88.6(41-322)$ & & & \\
$\quad$ Middle calyx & $70.2(38-221)$ & & & \\
$\quad$ Lower calyx & $66.7(39-191)$ & & & \\
\hline
\end{tabular}

*: data is presented as mean (minimum-maximum)

$p$ values $<0.05$ are given in italics

stones was higher than that of the distal stones. On the other hand, Lu et al. ${ }^{18}$ showed that SFR rates after ESWL were similar for proximal, middle, and distal ureteral stones. Our overall success rate was $87.2 \%$ for the ureteral stones. Important factors explaining the success of ESWL in children are: although the child ureter has a narrower lumen than the adult ureter, it is shorter, more elastic and stretchable, making the passage of the fragments easier and ureteral stone impaction more difficult, and shock wave transmission in the child's body is better. ${ }^{19}$ It is estimated that $10-20 \%$ of the shock wave energy disappears as it passes through every $6 \mathrm{~cm}$ of body tissue. ${ }^{20}$ The important effect of stone location and calyx anatomy on stone clearance has been revealed previously ${ }^{21,22}$; in particular, lower calyx location was noted as a negative factor for stone clearance and some authors mentioned the importance of the infundibulopelvic angle. ${ }^{23}$ The European Association of Urology (EAU) 2017 Pediatric Urology guidelines state that renal pelvis and upper calyx stones respond better to ESWL than other stones. ${ }^{24}$ The SFR was about 90\% for the renal pelvis and upper ureteral stones but between $50 \%$ and $62 \%$ for the lower calyx stones. ${ }^{25}$ Although we did not measure the infundibulopelvic angle in our patients, our SFRs were consistent with the guidelines and the rate was around $84-89 \%$ in the renal pelvis and upper ureter and $52 \%$ in the lower calyx.

In the EAU guidelines, SFRs for stones $<1 \mathrm{~cm}$, $1-2 \mathrm{~cm}$, and $>2 \mathrm{~cm}$ and overall are reported to be around $90 \%, 80 \%, 60 \%$, and $80 \%$, respectively. In addition, as the stone size increases, the necessity of additional interventions also increases. ${ }^{25,26} \mathrm{We}$ found that stone size is an important factor for stone-free status in multivariate analysis. Our study proposes a different measurement of cutoff values for both kidney and ureteral stones for pediatric ESWL success. In our study, we found that SFR was higher in patients treated with the new generation device. Although the effect of developing technology is undeniable, we believe that the lower BMI of the patients 
Table VI. Comparison of stone-free rates and demographic characteristics of patients according to different lithotriptor devices.

\begin{tabular}{|c|c|c|c|c|}
\hline Variable & Total & Group A & Group B & $\mathrm{P}$ value \\
\hline Number of patients, $\mathrm{n}(\%)$ & $1012(100)$ & $607(60.0)$ & $405(40.0)$ & 0.039 \\
\hline Stone-free rate, $\mathrm{n}(\%)$ & $815(80.5)$ & $443(73.0)$ & $372(92.0)$ & 0.042 \\
\hline Age, years* & $6.6(0.58-18)$ & $6.9(0.58-16)$ & $6.4(1.9-18)$ & 0.207 \\
\hline Gender, n (\%) & & & & 0.311 \\
\hline Boys & $644(63.6)$ & $311(51.2)$ & $333(82.2)$ & \\
\hline Girls & $368(36.4)$ & $296(48.8)$ & $72(17.8)$ & \\
\hline Body mass index, $\mathrm{kg} / \mathrm{m}^{2 *}$ & $23.2(17.3-28.6)$ & $26.8(19.1-29.0)$ & $22.1(17.3-27.1)$ & 0.008 \\
\hline Family history, n (\%) & & & & 0.544 \\
\hline Yes & $237(23.4)$ & $118(19.4)$ & $119(29.3)$ & \\
\hline No & $775(76.6)$ & $489(80.6)$ & $286(70.7)$ & \\
\hline Previous surgery, n (\%) & & & & 0.027 \\
\hline Yes & $155(15.3)$ & $129(21.2)$ & $26(6.4)$ & \\
\hline No & $857(84.7)$ & $478(40.8)$ & $379(55.2)$ & \\
\hline \multicolumn{5}{|c|}{ Congenital kidney anomaly, n (\%) } \\
\hline Yes & $33(3.2)$ & $20(3.3)$ & $13(3.2)$ & 0.051 \\
\hline No & $979(96.8)$ & $587(96.7)$ & $467(96.8)$ & \\
\hline \multicolumn{5}{|l|}{ Stone location, $\mathrm{n}(\%)$} \\
\hline Kidney & 915 (90.4) & $535(88.1)$ & $380(94.0)$ & 0.021 \\
\hline Renal pelvis & $584(63.8)$ & $305(57.0)$ & 279 (73.4) & 0.034 \\
\hline Upper calyx & $172(18.8)$ & $44(8.2)$ & $128(33.7)$ & 0.029 \\
\hline Middle calyx & $122(13.4)$ & $40(7.4)$ & 82 (21.6) & 0.047 \\
\hline Lower calyx & $37(4.0)$ & $20(3.7)$ & $17(4.4)$ & 0.628 \\
\hline Ureter & $97(9.6)$ & $52(8.5)$ & 45 (11.8) & 0.424 \\
\hline Proximal ureter & $76(78.3)$ & $37(71.1)$ & 39 (86.7) & 0.011 \\
\hline Distal ureter & $21(21.7)$ & $15(28.9)$ & $6(13.3)$ & 0.038 \\
\hline Stone size, $\mathrm{mm}^{2 *}$ & $118.5(12-1680)$ & & & \\
\hline Kidney & & $128.6(34-1680)$ & $89.1(12-1240)$ & 0.023 \\
\hline Renal pelvis & $127(25-1680)$ & & & \\
\hline Upper calyx & $90.7(25-300)$ & & & \\
\hline Middle calyx & $74.7(12-274)$ & & & \\
\hline Lower calyx & $75.4(25-625)$ & & & \\
\hline Ureter & & $45.8(28-102)$ & $56.6(20-121)$ & 0.319 \\
\hline Proximal ureter & $61.4(20-121)$ & & & \\
\hline Distal ureter & $31.4(25-50)$ & & & \\
\hline
\end{tabular}

Group A: patients treated with the Dornier MPL 9000 between March 1991 and November 2010.

Group B: patients treated with the ELMED Multimed Classic between November 2010 and November 2017.

*: data is presented as mean (minimum-maximum)

$p$ values $<0.05$ are given in italics

in this group, the smaller number of patients with previous surgery, the greater proportion of patients with renal pelvis and upper-middle calyx stones and smaller size of kidney stones might ultimately have significantly impacted this result. With the development of surgical technique, ESWL has been replaced with percutaneous surgery in the modern era. 
In pediatric patients, both KUB and ultrasonography are commonly used methods for post-ESWL evaluation. Because of the lower diagnostic capability of ultrasonography in ureteral stones, more accurate results can be obtained by using these two methods in combination. In our study, we found that the factors affecting the SFR were similar in the subgroup analysis after excluding the patients evaluated with only KUB.

Two important studies have revealed contradictory results regarding the number of stones. Dogan et al. ${ }^{11}$ showed significantly lower stone-free rates in multiple stones in a comparative analysis of the effective factors for stone clearance after a single session, whereas Alsagheer et al. ${ }^{12}$ showed that stone number is not an important predictor for ESWL success in univariate analysis. Two nomogram studies have indicated that the presence of a single stone is a favorable factor for stone clearance in the pediatric ESWL. ${ }^{11,27}$ The number of stones in our patients ranged from 1 to 5 and we found that the number of stones did not affect SFR in the ureteral stones, though it affected the SFR in the kidney stones significantly. In the multivariate analysis, the effect of the number of stones for SFR was statistically non-significant. We believe that the effect of the number of stones was not significant in the ureteral stones because the maximum number of ureteral stones was two and the overall SFR in the ureter was higher than in the kidney.

The pre-ESWL DJS placement rate is up to $15.4 \%$ in the literature. This intervention requires general anesthesia and has mild complications, meaning that one should perform it only in the case of absolute indications. The stent does not affect the SFR, but the overall complication rate is higher and the hospital stay is longer in patients who are not stented. ${ }^{28,29}$ The prevalence of DJS application before ESWL was slightly lower $(9.5 \%)$ in our patient group than in the literature. Steinstrasse was seen in only 20 children who underwent ESWL and only three of them had a DJS. The mean stone size was 239 $\mathrm{mm}^{2}$ in patients who underwent pre-procedural DJS, well above the overall average.

The response of cystine, calcium oxalate monohydrate, and calcium phosphate stones to ESWL is quite poor. ${ }^{29}$ In our study, the SFR was significantly lower in the calcium phosphate, calcium oxalate, and cystine stones, consistent with the literature. The reason why there was no significant difference in multivariate analysis was that stone analysis could be performed in only $66(6.52 \%)$ patients. Patients known to have these stone compositions might be better directed to other treatment alternatives. The main reason for why stone analysis was conducted in such a small group of patients was the referral of the patients to an external center because the analysis could not be performed in our hospital. Another reason is the difficulty in obtaining stone fragments in this age group.

This study has several limitations. First, it's retrospective nature. Second, the ESWL procedure was performed by a different urologist each month; this factor can also affect the results. Another limitation is the lack of metabolic evaluation data of patients. Metabolic evaluation is absolutely mandatory in pediatric stone patients. However, after ESWL, we refer our patients to the pediatric nephrology clinic for metabolic evaluation and further treatment. Therefore, this data was not available. The strengths of our study are its long-term extent, excessive patient number, and inclusion of several parameters that have not been found together in many studies.

We concluded that ESWL is an effective and safe treatment modality in the pediatric age group that provides high SFRs. However, sufficient technical equipment and increased experience affect the outcomes positively, and age, BMI, and stone location, size, and composition are significant factors that predict the success of ESWL. 


\section{REFERENCES}

1. Cohen TD, Ehreth J, King LR, Preminger GM. Pediatric urolithiasis: medical and surgical management. Urology 1996; 47: 292-303.

2. Chaussy C, Schmiedt E, Jocham B, Brendel W, Forssmann B, Walther V. First clinical experience with extracorporeally induced destruction of kidney stones by shock waves. J Urol 1982; 127: 417-420.

3. Newman DM, Coury T, Lingeman JE, et al. Extracorporeal shock wave lithotripsy experience in children. J Urol 1986; 136(1 Pt 2): 238-240.

4. Muslumanoglu AY, Tefekli A, Sarilar O, Binbay M, Altunrende F, Ozkuvanci U. Extracorporeal shock wave lithotripsy as first line treatment alternative for urinary tract stones in children: a large scale retrospective analysis. J Urol 2003; 170: 2405-2408.

5. Badawy AA, Saleem MD, Abolyosr A, et al. Extracorporeal shock wave lithotripsy as first line treatment for urinary tract stones in children: outcome of 500 cases. Int Urol Nephrol 2012; 44: 661666.

6. Marberger M, Türk C, Steinkogler I. Piezoelelectric extracorporeal shock wave lithotripsy in children. J Urol 1989; 142(2 Pt 1): 349-352.

7. Osti AH, Hofmockel G, Frohmüller H. Ureteroscopic treatment of ureteral stones: only an auxiliary measure of extracorporeal shockwave lithotripsy or a primary therapeutic option? Urol Int 1997; 59: 177181.

8. El-Assmy A, El-Nahas AR, Abou-El-Ghar ME, Awad BA, Sheir KZ. Kidney stone size and hounsfield units predict successful shockwave lithotripsy in children. Urology 2013; 81: 880-884.

9. Shokeir AA, Sheir KZ, El-Nahas AR, El-Assmy AM, Eassa W, El-Kappany HA. Treatment of renal stones in children: a comparison between percutaneous nephrolithotomy and shock wave lithotripsy. J Urol 2006; 176: 706-710.

10. Turna B, Tekin A, Yağmur İ, Nazlı O. Extracorporeal shock wave lithotripsy in infants less than 12-month old. Urolithiasis 2016; 44: 435-440.

11. Dogan HS, Altan M, Citamak B, Bozaci AC, Karabulut E, Tekgul S. A new nomogram for prediction of outcome of pediatric shock-wave lithotripsy. J Pediatr Urol 2015; 11: 84. e1-6.

12. Alsagheer G, Abdel-Kader M, Hasan A, et al. Extracorporeal shock wave lithotripsy (ESWL) monotherapy in children: predictors of successful outcome. J Pediatr Urol 2017; 13: 515.e1-515.e5.
13. El-Nahas AR, El-Assmy AM, Mansour O, Sheir $\mathrm{KZ}$. A prospective multivariate analysis of factors predicting stone disintegration by extracorporeal shock wave lithotripsy: the value of high-resolution noncontrast computed tomography. Eur Urol 2007; 51: 1688-1694.

14. McAdams S, Shukla AR. Pediatric extracorporeal shock wave lithotripsy: predicting successful outcomes. Indian J Urol 2010; 26: 544-548.

15. Abdel-Khalek M, Sheir KZ, Mokhtar AA, Eraky I, Kenawy M, Bazeed M. Prediction of success rate after extracorporeal shock-wave lithotripsy of renal stones-a multivariate analysis model. Scand J Urol Nephrol 2004; 38: 161-167.

16. Tunc L, Tokgoz H, Tan MO, Kupeli B, Karaoglan U, Bozkirli I. Stones in anomalous kidneys: results of treatment by shock wave lithotripsy in 150 patients. Int J Urol 2004; 11: 831-836.

17. Bader MJ, Eisner B, Porpiglia F, Preminger GM, Tiselius HG. Contemporary management of ureteral stones. Eur Urol 2012; 61: 764-772.

18. Lu J, Sun X, He L, Wang Y. Efficacy of extracorporeal shock wave lithotripsy for ureteral stones in children. Pediatr Surg Int 2009; 25: 1109-1112.

19. Jayanthi VR, Arnold PM, Koff SA. Strategies for managing upper tract calculi in young children. J Urol 1999; 162(3 Pt 2): 1234-1237.

20. Gofrit ON, Pode D, Meretyk S, et al. Is the pediatric ureter as efficient as the adult ureter in transporting fragments following extracorporeal shock wave lithotripsy for renal calculi larger than $10 \mathrm{~mm}$ ? J Urol 2001; 166: 1862-1864.

21. Ather MH, Noor MA. Does size and site matter for renal stones up to 30-mm in size in children treated by extracorporeal lithotripsy? Urology 2003; 61: 212215.

22. Önal B, Demirkesen O, Tansu N, Kalkan M, Altintaş $\mathrm{R}$, Yalçin V. The impact of caliceal pelvic anatomy on stone clearance after shock wave lithotripsy for pediatric lower pole stones. J Urol 2004; 172: 10821086.

23. Tan MÖ, Karaoğlan Ü, Şen I, Deniz N, Bozkırlı I. The impact of radiological anatomy in clearance of lower calyceal stones after shock wave lithotripsy in paediatric patients. Eur Urol 2003; 43: 188-193.

24. Turk C, Petrik A, Sarica K, et al. EAU Guidelines on Interventional Treatment for Urolithiasis. Eur Urol 2016; 69: 475-482. 
25. Demirkesen O, Önal B, Tansu N, Altintaş R, Yalçın $\mathrm{V}$, Öner A. Efficacy of extracorporeal shock wave lithotripsy for isolated lower caliceal stones in children compared with stones in other renal locations. Urology 2006; 67: 170-174.

26. Hochreiter WW, Danuser H, Perrig M, Studer UE. Extracorporeal shock wave lithotripsy for distal ureteral calculi: what a powerful machine can achieve. J Urol 2003; 169: 878-880.

27. Onal B, Tansu N, Demirkesen O, et al. Nomogram and scoring system for predicting stone-free status after extracorporeal shock wave lithotripsy in children with urolithiasis. BJU Int 2013; 111: 344-35.
28. Tan A, Al-Omar M, Watterson J, Nott L, Denstedt J, Razvi H. Results of shockwave lithotripsy for pediatric urolithiasis. J Endourol 2004; 18: 527-530.

29. Lottmann H, Traxer O, Archambaud F, MercierPageyral B. Monotherapy extracorporeal shock wave lithotripsy for the treatment of staghorn calculi in children. J Urol 2001; 165(6 Pt 2): 2324-2327. 